\title{
Transporte de cabotagem no Porto de Suape, Pernambuco: uma pesquisa exploratória
}

\author{
Simone Maria Lucena Cruz ${ }^{\mathrm{a}}$, Maria Creuza Borges de Araújo ${ }^{\mathrm{b} *}$, Luciana Hazin Alencarc \\ asimonelcruz@gmail.com, UFPE, Brasil \\ b*mariacreuzaborges@yahoo.com.br, UFPE, Brasil \\ calencarlh@gmail.com, UFPE, Brasil
}

\begin{abstract}
Resumo
A utilização de contêineres tem reflexos expressivos no volume de produtos movimentados para importação e exportação nos portos brasileiros. Nesse sentido, a movimentação de cargas via cabotagem tem-se mostrado uma alternativa viável para o transporte de cargas no pais. Este trabalho teve como objetivo identificar os fatores de competitividade das empresas de cabotagem do Porto de Suape, Pernambuco. Para tanto, aplicou-se um questionário para coleta de dados em empresas clientes do porto e uma análise estatística para a obtenção de um diagnóstico sobre este modal. Os resultados fornecem uma visão dos clientes quanto à cabotagem, assim como dos aspectos que trazem diferenciação à atividade principal de transporte realizada pelo armador e que têm maior importância para os clientes. Tais resultados permitem aos armadores reavaliar sua estratégia de atuação no mercado e, aos clientes, uma visão ampla, que auxiliará na tomada de decisão em relação à estratégia de transporte escolhida.
\end{abstract}

Palavras-chave

Cadeia de suprimentos. Logística. Transporte.

\section{Introdução}

O sistema de transporte tem fundamental importância para a logística, desde o abastecimento da matéria-prima até a entrega do produto ao cliente final. Os sistemas de gerenciamento de transporte e armazenagem são tecnologias chave usadas para gerir o fluxo físico de mercadorias ao longo da cadeia de abastecimento (Wanke \& Affonso, 2011). Dessa forma, o transporte pode ser determinante para a inserção ou aumento da participação de produtos em determinados mercados.

Além disso, o transporte possui grande impacto financeiro na economia das organizações e do país. De acordo com estudos realizados pela Confederação Nacional do Transporte - CNT (Confederação Nacional dos Transportes, 2006), os custos logísticos no Brasil, estimados para o ano de 2008, atingiram um valor equivalente a 11,6\% do Produto Interno Bruto (PIB) daquele ano, ou seja, $\mathrm{R} \$ 349,0$ bilhões, sendo o transporte o item de maior representatividade, com 6,9\% do PIB, R\$ 207 bilhões.
Dessa forma, observa-se que a escolha do melhor modal para cada realidade econômica, roteiro e infraestrutura regional poderá resultar em melhor desempenho logístico. Nesse sentido, Fachinello \& Nascimento (2008) afirma que o uso mais eficiente dos modais de transporte constitui uma oportunidade para aumentar a competitividade das organizações por meio da redução de custos.

Entretanto, nota-se que embora o Brasil possua uma extensa costa litorânea propícia para 0 transporte maritimo as empresas brasileiras utilizam majoritariamente o modal rodoviário. Atualmente, esses modais respondem por $12 \%$ e $58 \%$ das movimentações de cargas, respectivamente (Guia marítimo, 2011). De acordo com a Log In (Logística Intermodal S/A, 2005), ao longo do ano de 2010, o mercado potencial para a cabotagem não atendido por esse modal correspondia a 1,2 milhão de Twenty Equivalent Units (TEUs), o que demonstra grande potencial de crescimento.

Nesse sentido, Carvalho (2009) afirma que o transporte marítimo de cabotagem é uma alternativa 
viável para integrar cadeias de suprimentos em diversos setores brasileiros, o que pode auxiliar na redução de custos e na contribuição ao meio ambiente. Além disso, segundo o Instituto de Pesquisa Econômica Aplicada - IPEA (Instituto de Pesquisa Aplicada, 2005), fatores macroeconômicos, como competitividade, redução da inflação, queda da taxa de câmbio e falta de recursos para a recuperação da malha viária ajudaram a cabotagem nas últimas décadas.

Outro aspecto importante é a retomada da indústria naval brasileira, que pode ser percebida no aumento das encomendas para os estaleiros nacionais. Alguns incentivos e iniciativas como o Programa de Mobilização da Indústria de Óleo e Gás (Prominp), o Programa de Modernização e Expansão da Frota (Promef) e as recentes descobertas na camada do pré-sal vêm impulsionando o setor (Portal Naval, 2010). Ademais, segundo a Log ln (Logística Intermodal S/A, 2010), há uma crescente tendência do processo de conteinerização de cargas, em que a padronização no acondicionamento de produtos se traduz em menores custos envolvidos na sua movimentação, com um potencial cerca de três vezes maior que o atual para esse tipo de transporte, apresentando possibilidades de captura de participação de mercado sobre o modal rodoviário.

Ademais, observa-se que, para ganhar e fidelizar clientes, é necessário que os transportadores de cabotagem observem quais os critérios definidos pelos clientes para a escolha do armador. De acordo com Almeida (2001), os aspectos relacionados à competitividade do sistema como um todo devem ser considerados em um processo decisório. Entre tais critérios podem-se citar preço do frete, pré-reserva de espaço no navio, utilização de navio e contêiner próprios, entre outros. Além disso, fatores como cumprimento do horário de coleta e/ou entrega, disponibilidade de contêiner e de veículo, aparência do contêiner e do veículo para realizar a coleta e entrega, cordialidade do motorista e da equipe de "ova" e "desova" diferenciam a atividade dos armadores e agregam valor para o cliente,

Finalmente, embora o termo cabotagem não seja novo, existe pouca literatura sobre $o$ assunto no Brasil, o que traz a necessidade de trabalhos nesta área para um melhor conhecimento do tema, com suas vantagens, desvantagens e escopo no país.

Nesse contexto, esta pesquisa teve como finalidade identificar os fatores de competitividade do transporte marítimo de cabotagem em empresas que utilizam o serviço de cargas geral em contêineres via cabotagem, excluindo-se cargas a granel ou com dimensões que não possam ser manuseadas em contêiner. Desse modo, foram identificadas as vantagens e desvantagens desse modal em relação ao rodoviário, quais os fatores agregam valor a el, assim como os armadores mais utilizados e os aspectos que aumentam sua competitividade.

\section{Transportes na cadeia de suprimentos}

A cadeia de suprimentos abrange todas as atividades relacionadas com o fluxo e transformação de mercadorias, desde o estágio da matéria-prima (extração) até o usuário final, bem como os respectivos fluxos de informação (Ballou, 2006). Dessa forma, engloba todos os estágios ligados ao atendimento de um pedido, desde o primeiro fornecedor até o cliente final, observando os fluxos externos à empresa, enquanto que o papel da gestão logística está relacionado ao atendimento do pedido a partir do gerenciamento dos fluxos internos. Nesse sentido, Ching (2010) afirma que essa cadeia procura administrar as relações de cooperação com o objetivo de aumentar a satisfação e a retenção dos clientes atuais e obter novos clientes, a partir do gerenciamento eficaz de toda a cadeia logística e da busca pelo benefício de todos os envolvidos. Pois, conforme Bandeira et al. (2012), existem evidências teóricas de que a aplicação de práticas de gestão baseadas na cooperação, comprometimento e confiança implicam em melhoria do desempenho da cadeia de suprimentos.

Segundo Bowersox et al. (2006), a logística é um subconjunto da estrutura mais abrangente de uma cadeia de suprimentos. De acordo com o Council of Logistics Management (Council of Supply Chain Management Professionals, 2010), a logística é considerada o processo de planejamento, implementação e controle do transporte e armazenagem eficiente e eficaz de mercadorias, serviços e informação, relacionadas do ponto de origem até o ponto de consumo, com o propósito de atender as exigências dos clientes. Nesse contexto, as companhias dependem de seus sistemas logísticos para mover produtos e materiais entre os parceiros na cadeia de suprimentos e para gerenciar o fluxo de informações necessário para executar essas tarefas (Bozarth \& Handfield, 2008).

Um elemento de elevada importância no contexto da logística é o transporte, que atua no abastecimento, movimentação interna, distribuição física e entrega ao destino final. Um bom sistema de transporte nas atividades logísticas pode fornecer melhor eficiência logística, redução de custos operacionais e promover qualidade no serviço (Tseng et al., 2005).

Assim, a escolha dos modais a serem utilizados é de extrema importância, pois, segundo Fachinello \& Nascimento (2008), o seu uso eficiente é uma oportunidade para o aumento da competitividade das empresas, a partir da redução dos custos. 
Nesse sentido, consideram-se cinco modos básicos de transporte: rodoviário, ferroviário, dutoviário, aéreo e aquaviário. 0 modal aquaviário divide-se em: transporte marítimo, fluvial e lacustre. Conforme Mendonça \& Keedi (1997), no transporte marítimo tem-se a navegação de longo curso (internacional) e a navegação de cabotagem (nacional). Neste trabalho será abordado o transporte de cabotagem.

Ballou (2006) afirmam que na escolha do serviço de transporte devem-se observar as seguintes características: preço, tempo médio em trânsito, variabilidade de tempo em trânsito e perdas e danos. Dessa forma, é necessário o conhecimento dos fatores de desempenho de cada modal para a escolha daquele mais adequado à situação.

\section{Cabotagem}

Segundo Oliveira (2000), o termo cabotagem significa "navegação entre cabos e portos do mesmo país”. Conforme a lei n. 10.863 (Brasil, 2004), "navegação de cabotagem é aquela realizada entre os portos brasileiros, utilizando exclusivamente a via marítima ou a via marítima e as interiores".

De acordo com Moura \& Botter (2011), o Brasil possui dimensões continentais e o transporte de produtos pelo país enfrenta estradas em péssimas condições, o que eleva o custo do transporte, reduzindo a competitividade, principalmente para longas distâncias. Dessa forma, os autores afirmam que a cabotagem é um meio não só de tornar o modal marítimo competitivo mas, quando aliada aos demais modais, pode contribuir para redução dos custos logísticos nacionais, reduzir avarias de transporte e perdas de cargas. Segundo Fadda (2007), uma das principais características da cabotagem é que ela é a forma mais econômica de movimentar grandes volumes e tonelagem de carga por longas distâncias e de uma única vez, além de ser utilizada para todos os tipos de carga.

Nos últimos anos, estudos têm sido desenvolvidos sobre a cabotagem no Brasil e a maioria aponta sua viabilidade econômica a partir do menor custo de frete. Segundo pesquisa da CNT (Confederação Nacional dos Transportes, 2006), a cabotagem é considerada mais vantajosa do que outros meios de transporte, de acordo com as características de contratação, em relação ao custo do frete $(41,3 \%)$, à segurança da carga $(25,9 \%)$, à confiabilidade dos prazos $(12,2 \%)$ e ao nível de avarias (11,1\%).

Na cabotagem são movimentados diferentes tipos de cargas, classificadas como carga geral e granéis, que podem apresentar variações com relação a sua movimentação, de acordo com o tipo de navegação.
Este trabalho tem como foco a carga geral, que é aquela embarcada e acondicionada para o embarque, o transporte e a descarga, podendo ser unitizada ou solta, devidamente contada e identificada. Nesse caso, observou-se a carga acondicionada em contêineres.

0 contêiner é um equipamento do veículo transportador, embora tenha uma função em termos práticos de embalagem, pois facilita o transporte de mercadorias (Mendonça \& Keedi, 1997). De acordo com Notteboom \& Rodrigue (2008), o uso de contêineres aumenta as vantagens competitivas, com interação mais eficiente entre os sistemas de distribuição, maior velocidade e redução dos custos. Ademais, apresenta vantagens em relação a outros equipamentos de unitização, tais como inviolabilidade, rapidez, segurança e redução de custos nos transporte (Mendonça \& Keedi, 1997).

Nesse contexto, um fator de suma importância para esse modal é a situação dos portos, pois, segundo Salido et al. (2012), a gestão eficiente de contêineres nos portos assegura a confiabilidade, data de entrega e quantidade de manuseio, melhorando sua produtividade. Atualmente existem 37 portos públicos marítimos e fluviais no Brasil, dos quais 18 são delegados, concedidos, ou têm sua operação autorizada à administração dos governos estaduais e municipais, além de 42 terminais de uso privado e três complexos portuários que operam por concessão à iniciativa privada.

Vale ressaltar que as mudanças no sistema portuário brasileiro tiveram relevante impacto para a utilização da cabotagem. A regulamentação da Lei de Modernização dos Portos, lei n. 8.630 (Brasil, 1993), iniciou o processo de melhoria dos portos brasileiros e retomada da cabotagem, além da instituição de novos atores: o Conselho de Autoridade Portuária (CAP), o Órgão Gestor de Mão de Obra (OGMO) e o Operador Portuário. Além da lei, decretos e resoluções posteriores aperfeiçoaram o marco institucional e o equilíbrio econômico-financeiro dos contratos na busca por eficiência e competitividade.

\subsection{Terminologias utilizadas para a cabotagem}

Neste trabalho serão abordados aspectos inerentes a terminologias específicas do transporte de cabotagem importantes para o entendimento do assunto. Algumas modalidades, bem como alguns termos utilizados no dia a dia dos profissionais que atuam direta ou indiretamente com o transporte marítimo de cabotagem não foram encontrados na literatura, mas, com base no conhecimento de especialista e de documentos, foram incorporados ao questionário 
utilizado para o levantamento de dados do presente estudo, e são descritos a seguir.

- Adicional de Frete para Renovação da Marinha Mercante (AFRMM): segundo a lei n. 10.893 (Brasil, 2004), o governo federal instituiu uma taxa paga pelo importador e/ou consignatário denominada AFRMM, que é destinada a atender os encargos da intervenção da união no apoio ao desenvolvimento da marinha mercante e da indústria da construção e reparação naval brasileiras e constitui a fonte básica do Fundo da Marinha Mercante (FMM).

- Departamento da Marinha Mercante (DMM): segundo Goularti Filho (2010), o DMM tem como objetivo controlar os recursos oriundos do AFRMM.

- Conhecimento de Transporte Aquaviário de Carga (CTAC): de acordo com a portaria n. 72 (Brasil, 2008), no transporte interestadual e intermunicipal de cargas nacionais em caráter comercial, o CTAC substituirá o Conhecimento de Embarque.

- Siscomex-Carga (Siscarga): é o resultado da integração do Sistema Mercante com o módulo de controle de carga aquaviário do Sistema Integrado de Comércio Exterior, a partir da qual o Sistema Mercante passou a receber todas as informações necessárias à Receita Federal do Brasil para o controle aduaneiro de embarcações, cargas e unidades de carga no transporte aquaviário (Brasil, 2008).

- Formulário Único de Entrega (FUE): documento utilizado pelo Tecon Suape para realizar o controle de entrega dos contêineres no terminal.

- Lead time: é o tempo gasto para entrega do produto, desde a realização do pedido até o recebimento pelo cliente final.

- Detation e demurrage: conforme Keedi (2006), detation diz respeito à multa aplicada ao embarcador por não realizar a devolução do contêiner cheio para a realização do embarque, enquanto demurrage é a multa aplicada ao recebedor por não devolver o contiêner no prazo estabelecido.

- Schedule: é a programação dos navios, a partir da qual o cliente obtém informações acerca do navio e da viagem, com as datas previstas para a chegada e saída da embarcação em todos os portos.

- Booking: termo utilizado pelos armadores para a confirmação da reserva de espaço solicitada pelo cliente para o transporte de suas mercadorias no navio.

- Bunker. representa o tipo de combustível a bordo do navio, compartimento ou tanque para a armazenagem de combustivel.

Podem-se citar ainda Dangerous Cargo Manifest (manifesto de carga perigosa), gate (portão ou agulha de aparelho de mudança de via férrea e cancela) e deadline (prazo de entrega ou prazo final para o pagamento de uma obrigação).

0 entendimento dos termos citados é de fundamental importância para os profissionais que atuam na área, pois seu desconhecimento pode comprometer a operação e/ou gerar custos extras, não previstos na contratação do serviço de cabotagem.

Sobre as modalidades utilizadas no levantamento de dados do presente trabalho, vale esclarecer que os armadores de cabotagem utilizam como base as modalidades aplicadas no transporte marítimo de longo curso. Segundo Keedi (2006), os termos porta e porto designam os locais de consolidação - "ova” (colocação da carga dentro do contêiner) - e desconsolidação - "desova” (retirada da carga de dentro do contêiner) -, em termos da prática, os quais são definidos entre as partes envolvidas: o embarcador ou consignatário e o armador. Na modalidade "porta", o contêiner seguirá até o domicílio do cliente onde será "ovado" ou "desovado". Outra modalidade existente é a de "porto", na qual o contêiner é "ovado" ou "desovado" em algum terminal no porto. De acordo com o mesmo autor, há quatro combinações possíveis: porta a porta, porta a porto, porto a porto e porto a porta. A modalidade "porta a porta" é a que compreende um maior grau de responsabilidades assumidas pelo armador, pois, após a efetuação do pedido de reserva, caberão a ele todas as providências necessárias para o efetivo transporte, cumprimento dos prazos de coleta e entrega, controle do tempo livre de detation e de demurrage, bem como informação ao cliente em todas as fases do processo.

No transporte de cabotagem, essas modalidades sofreram algumas adaptações a fim de possibilitar um melhor entendimento quanto à responsabilidade na realização do transporte da "casa" do cliente ao porto e do porto à "casa" do cliente, assim como da responsabilidade de "ovar" e "desovar" o contêiner. Dessa forma, existem as seguintes modalidades possíveis no transporte marítimo de cabotagem: porta a porta com "ova” e "desova"; porta a porta sem "ova" e sem "desova”; porta a porta com "ova" e sem "desova"; porta a porta sem "ova" e com "desova"; porto a porto sem "ova" e sem "desova”; porto a porta sem "ova” e com "desova"; porta a porto sem "ova" e sem "desova"; porta a porto com "ova" e sem "desova"; píer a píer com "ova" e "desova" no porto; píer a porta com "ova" no porto e sem "desova"; e porta a píer com "ova" no cliente e "desova” no porto. Após o esclarecimento dos termos e das modalidades usuais entre os que trabalham com cabotagem, partiu-se para a estruturação do questionário. 


\section{Metodologia}

Para a realização deste trabalho foi realizada uma análise exploratória sobre o tema em questão. Segundo Souza et al. (2002), as principais características dessa abordagem são: produz essencialmente descrições dos eventos investigados; sugere explicações causais, mas sem confirmá-las; e não requer muita teorização a priori. Além disso, Vergara (2009), afirma que a investigação exploratória não deve ser confundida com a leitura exploratória, pois ela é realizada em área onde há pouco conhecimento sistematizado e acumulado e, pela natureza de sondagem, não comporta hipóteses. Segundo o autor, as hipóteses poderão surgir durante a análise ou no final dela.

Dessa forma, a primeira etapa consistiu na realização de uma pesquisa bibliográfica, a partir de livros, artigos, sites e informações disponibilizadas por órgãos públicos e privados, com o intuito de aprimorar o conhecimento acerca do tema pesquisado e, assim, elaborar um questionário que atendesse aos objetivos do estudo. Em seguida, realizou-se uma pesquisa de campo, com a aplicação de questionários em empresas localizadas no Porto de Suape (Pernambuco) que atuam no recebimento ou embarque de produtos, com o intuito de identificar os fatores de competitividade do transporte marítimo de cabotagem realizado por essas empresas.

\subsection{Coleta dos dados}

Para a coleta de dados foi aplicado um questionário autoadministrado, elaborado com base na revisão da literatura e conhecimentos primários acerca do tema.

0 questionário foi dividido em quatro partes, conforme o Tabela 1.

Após a elaboração do questionário, foram realizados dois pré-testes em três empresas previamente selecionadas, com o objetivo de avaliar a qualidade e clareza das perguntas, a exatidão e coerência das respostas, assim como de estimar o tempo médio de resposta.
Em seguida, uma amostra não probabilística foi definida. 0 universo apresentado pela Tecon Suape totalizou 60 clientes que movimentaram carga em contêineres via cabotagem no ano de 2010 no terminal da empresa. E-mails foram enviados e ligações telefônicas realizadas para a identificação dos respondentes (profissional responsável pela contratação, gestão e/ou usuário do serviço de cabotagem). 0 questionário foi enviado para os respondentes identificados, utilizando-se uma ferramenta do Google. Do total de questionários enviados, 67\% foram respondidos, o que totalizou 30 empresas. 0 levantamento de campo foi realizado de julho a outubro de 2011.

\subsection{Análise dos dados}

Após a finalização da coleta de dados, foi realizada a codificação das variáveis. Para o tratamento estatístico dos dados utilizou-se o software Minitab versão 16.0. A análise dos dados foi realizada com base em indicadores da análise estatística descritiva (distribuição de frequência) e inferencial (teste t de student e correlação de Spearman).

0 coeficiente de correlação de Spearman ( $\rho$ ) é uma medida de correlação entre duas variáveis aleatórias e não paramétricas que são ordenáveis. 0 cálculo desse coeficiente baseia-se no ranking dos valores de x e y, de acordo com a fórmula exposta por Triola (2005):

$\rho=1-\frac{6 \sum d i^{2}}{\left(n^{3}-n\right)}$

onde:

$\rho=$ coeficiente de correlação de Spearman;

$\mathrm{di}=$ diferença entre as posições de cada valor de $X$ e cada valor de $Y$ correspondente;

$\mathrm{n}=$ número de pares de dados.

0 coeficiente de Spearman varia entre -1 e +1 , o que indica associações negativas ou positivas, respectivamente. Zero indica que não há correlação. Quanto mais próximo o coeficiente de correlação de Spearman estiver dos extremos $(-1$ ou +1$)$, mais forte é a correlação (Triola, 2005).

Tabela 1. Agrupamento das questões disponíveis.

\section{Grupo de questões}

Respondente

Empresa

Cabotagem na empresa

\section{Descrição}

Visão do perfil dos responsáveis pela contratação e/ou dos usuários dos serviços de cabotagem nas empresas entrevistadas, bem como seu grau de conhecimento acerca dos termos utilizados nesse modal.

Caracterizar as empresas pesquisadas com relação ao número de empregados, o setor de atuação e o impacto financeiro do custo de transporte nos produtos fabricados.

Identificar aspectos relativos à adequação operacional, bem como à demanda por nível de serviço.

Análise dos clientes sobre os armadores quanto aos ativos disponibilizados. 
Para facilitar a interpretação desse parâmetro, Finney (1980) publicou a tabela de coeficientes de módulos de Spearman (Tabela 2).

Para confirmar a existência de correlação, foi realizado o teste $t$ com base em duas hipóteses, validadas com o nível de significância de 95\% e 99\%:

Ho $=\rho=0 \rightarrow$ não há correlação;

$\mathrm{H}=\rho \neq 0 \rightarrow$ há correlação.

De acordo com Hair Junior et al. (2005), o teste $t$ é adequado a situações em que o tamanho da amostra é pequeno $(\mathrm{n} \leq 30)$ e o desvio padrão da população é desconhecido. Esse teste consiste em determinar um valor de t para o $\rho$ de Spearman encontrado e compará-lo com o t crítico tabelado (Triola, 2005), de acordo com a fórmula 2, a seguir:

$$
t=\frac{\rho}{\sqrt{\frac{1-\rho^{2}}{n-2}}}
$$

onde,

$\mathrm{t}=$ valor de $\mathrm{t}$ para $\rho$;

$\rho=$ coeficiente de correlação de Spearman;

$\mathrm{n}=$ número de pares de dados.

Neste trabalho realizou-se a verificação de relações para observar a correlação de variáveis não paramétricas e ordenáveis, o que justifica a aplicação do teste t de student e da correlação de Spearman para a análise inferencial dos dados.

\section{Análise dos dados e discussões}

A partir da pesquisa bibliográfica e dos dados levantados pelo questionário, realizou-se uma análise exploratória descritiva e inferencial acerca dos usuários da cabotagem no Porto de Suape quanto ao seu perfil e sua percepção sobre o uso desse modal de transporte (Cruz, 2011). Por ser realizada em um ambiente onde ainda existe pouco conhecimento sistematizado, a pesquisa não comporta hipóteses teóricas a serem testadas; as hipóteses surgem conforme a realização do estudo e análise dos dados.

\subsection{Análise estatística descritiva}

Inicialmente foi realizada a análise estatística descritiva dos dados, ressaltando-se o perfil da amostra, das empresas, as demandas por nível de serviço e a percepção/avaliação dos armadores.

Quanto ao perfil dos contratantes e/ou usuários do serviço de cabotagem, 78\% dos entrevistados são do sexo masculino, com idade entre 30 e 49 anos (65\%), possuem algum tipo de especialização, com experiência profissional na área de logística superior a nove anos e ocupam cargos gerenciais e/ou de supervisão/coordenação. Com relação ao tempo em que trabalham na empresa, aproximadamente 50\% dos entrevistados atua há mais de nove anos na empresa, o que demonstra grau de maturidade profissional.

No que tange à informação acerca dos termos utilizados na área de navegação, a Tabela 3 expõe a média, a mediana e a moda para o seu conhecimento.

Nota-se que os termos deadline, demurrage, booking, gate, lead time, schedule, CTAC, Siscarga, AFRMM e bunker são os mais difundidos e conhecidos pelos profissionais. Verifica-se ainda que os termos menos conhecidos entre os entrevistados são: FUE, detation e DMM, com médias de 50\%, 47\% e $41 \%$, respectivamente. Tais resultados são confirmados pela mediana, que representa 0 para os termos DMM e detation e 0,5 para o termo FUE, e a moda, que obteve valor 0 para os primeiros e 1 para o último. Nesse sentido, percebe-se que os contratantes estão familiarizados com a maioria dos termos utilizados para cabotagem, o que pode ser explicado pelo tempo de atuação desses profissionais na área de logística e do tempo de utilização do modal pela empresa, que na maior parte das vezes é maior do que nove anos.

Ainda quanto ao perfil da amostra, verificou-se que a modalidade de cabotagem com maior utilização (84\%) é a "porta a porta".

Quanto ao perfil das empresas contratantes, 53\% delas são consideradas grandes, seguidas por

Tabela 2. Coeficiente de módulos de Spearman.

\begin{tabular}{cc}
\hline$[R]$ ou $[\rho]$ & Correlação \\
\hline$[0,9 ; 1]$ & Muito forte \\
{$[0,75 ; 0,9]$} & Forte \\
{$[0,5 ; 0,75]$} & Moderada \\
{$[0,25 ; 0,5]$} & Fraca \\
{$[0,0 ; 0,25]$} & Muito fraca \\
\hline
\end{tabular}

Fonte: Finney (1980).

Tabela 3. Conhecimento dos termos logísticos.

\begin{tabular}{lccc}
\hline \multicolumn{1}{c}{ Termos logisticos } & Média & Mediana & Moda \\
\hline Deadline & 1,00 & 1,00 & 1,00 \\
Demurrage & 1,00 & 1,00 & 1,00 \\
Booking & 0,97 & 1,00 & 1,00 \\
Gate & 0,94 & 1,00 & 1,00 \\
Lead time & 0,94 & 1,00 & 1,00 \\
Schedule & 0,94 & 1,00 & 1,00 \\
CTAC & 0,88 & 1,00 & 1,00 \\
Siscarga & 0,78 & 1,00 & 1,00 \\
AFRMM & 0,72 & 1,00 & 1,00 \\
Dangerous Cargo Manifest & 0,69 & 1,00 & 1,00 \\
Bunker & 0,63 & 1,00 & 1,00 \\
FUE & 0,50 & 0,50 & 1,00 \\
Detation & 0,47 & 0,00 & 0,00 \\
DMM & 0,41 & 0,00 & 0,00 \\
\hline
\end{tabular}

Fonte: autores. 
médias (25\%) e pequenas empresas (22\%). Com relação ao setor de atuação, 84\% são classificadas como indústrias, enquanto o restante enquadra-se nos ramos de comércio e serviços.

A fim de entender a importância da logística de transporte para a organização, verificou-se que o impacto financeiro do transporte sobre o valor dos produtos comprados e vendidos se enquadra, em $47 \%$ dos casos, entre 10\% e 30\%, o que implica que a decisão acerca do modal utilizado reflete-se diretamente no custo dos produtos movimentados pela empresa.

Com relação à demanda por nível de serviço, 43\% das empresas utilizam esse modal há mais de nove anos, $30 \%$ entre três enove anos e $27 \%$ há menos de três anos. Dessas, 81\% nunca tiveram descontinuidade no uso da cabotagem, o que demonstra uma forte consolidação dela na logística de transporte das empresas entrevistadas. Naquelas em que houve descontinuidade, mas que retornaram ao uso, 29,4\% atribuíram como principal motivo da pausa a baixa frequência dos navios, seguida da baixa confiabilidade nos prazos e preços de frete próximos ao do rodoviário, além da baixa opção de rotas, entrega superior a uma semana, baixo nível de informação sobre a carga e problemas climáticos.

Quanto à adequação operacional, ou seja, aos ajustes necessários à expedição/recebimento e à produção para atender aos prazos e condições inerentes ao modal marítimo, 78\% das empresas possuem período de adaptação inferior ou igual a um ano. Com relação às rotas mais utilizadas pelas empresas na cabotagem, 54\% estão compreendidas entre os trechos: Pernambuco ao Amazonas (25\%); São Paulo para Pernambuco (19\%) e Santa Catarina à Pernambuco (10\%). Os demais trechos obtiveram porcentagens abaixo de 7\%. Questionados sobre os trechos nos quais não há serviço de cabotagem mas existe demanda por parte das empresas, a rota com maior frequência ocorre de Pernambuco ao Pará, seguida da de Pernambuco com destino ao Maranhão (11\%) e da de Pernambuco ao Espírito Santo (7\%).

Tendo como referência o frete rodoviário, o percentual de ganho financeiro com o uso de cabotagem está entre 10\% e 20\% para 34\% e acima de 20\% para 35\% das empresas entrevistadas. Entretanto, identificou-se que 32\% das empresas transportam menos de $5 \%$ de suas mercadorias por esse modal, o que pode indicar uma ampla oportunidade de crescimento da participação da cabotagem na logística de transporte dessas organizações. Segundo as organizações, os principais fatores para o aumento da cabotagem seriam: menor custo do frete (29\%), maior confiabilidade nos prazos (16\%), menor tempo médio de entrega (15\%), maior disponibilidade de navios (14\%) e maior oferta de rotas (10\%).

No quesito percepção/avaliação sobre os armadores, os critérios apontados pelos clientes para a escolha do armador são: menor custo de frete total, associado à confiabilidade no cumprimento dos prazos e boa estrutura logística, com fatores como transporte rodoviário para a coleta e entrega e disponibilidade de contêineres. Com relação aos fatores que agregam valor ao serviço de transporte de cabotagem, segundo a percepção dos clientes, apontou-se: cumprimento de horário de coleta e/ou entrega (21\%), disponibilidade de contêineres (19\%), disponibilidade de veículos (19\%), aparência do contêiner (15\%), aparência do veículo para realizar a coleta e entrega (10\%), cordialidade do motorista (9\%) e equipe de "ova" e “desova” (7\%).

Verificou-se que para 35\% dos entrevistados os preços do transporte de cabotagem se mantiveram elevados nos últimos três anos. Trata-se de um importante indicativo para que os armadores revisem sua composição de custos, pois o preço do frete apareceu como fator determinante para o aumento do uso do modal e seleção de fornecedores de cabotagem. Por outro lado, 94\% das empresas que utilizam a cabotagem não obtêm nenhum tipo de desconto na contratação de seguros, enquanto 6\% alcançam descontos entre $0,1 \%$ e $0,5 \%$, o que demonstra a possibilidade de desconto no seguro.

Quanto aos armadores de cabotagem, a maioria das empresas utiliza a combinação do serviço de três armadores, o que mostra uma tendência de as empresas possuirem vários fornecedores de cabotagem dentro da sua cadeia logística.

Além disso, dados relacionados ao investimento dos armadores para melhoria do serviço demonstram que dentro de seu plano de investimento um determinado armador contempla a construção de cinco embarcações porta-contêineres e dois navios graneleiros, enquanto outro prevê a construção de quatro navios.

\subsection{Análise estatística inferencial}

Para a análise estatística inferencial dos dados foram observadas correlações entre algumas variáveis, expostas a seguir, com a utilização do cálculo da correlação de Spearman e o teste t de student.

Nesse sentido, a primeira correlação investigada ocorreu entre o conhecimento de cada um dos termos utilizados na cabotagem e a modalidade "porta a porta”. Para os termos Departamento da Marinha Mercante (DMM), Formulário Único de Entrega (FUE) e detation, observou-se uma correlação muito forte, com $\rho=0,98$. Ou seja, pode-se concluir, com 95\% 
e 99\% de probabilidade, que há correlação entre esses dados. Assim, formulou-se a hipótese H1: o baixo conhecimento de alguns termos logísticos de navegação está atrelado ao maior uso da modalidade "porta a porta".

Com $\rho=0,99$, a segunda correlação indica que, quanto maior a empresa, maior o impacto financeiro do custo do transporte no produto. Correlação que deu origem à $\mathrm{H} 2$ : quanto maior a empresa, maior é o impacto dos custos de transporte.

A terceira correlação relaciona o percentual de ganho financeiro com cabotagem e o percentual de produtos transportados por esse modal. 0 valor de $\rho=0,98$ indica que há uma correlação muito forte entre as variáveis, ou seja, quanto maior o uso da cabotagem, maior o ganho financeiro devido à redução do custo de transporte e, consequentemente, menor o custo do produto comprado e/ou vendido. Dessa forma, estruturou-se a hipótese $\mathrm{H} 3$ : as empresas que mais utilizam a cabotagem possuem menor custo de transporte na sua cadeia logística.

Com relação às variáveis escolha do armador versus critérios selecionados, a saber, preço do frete, pré-reserva de espaço e envio da confirmação de reserva no mesmo dia, observaram-se correlações muito fortes, com $\rho=0,93, \rho=0,91$ e $\rho=0,91$, respectivamente. Assim, identificou-se $\mathrm{H} 4$ : os armadores de cabotagem são escolhidos pelos clientes de acordo com os critérios de qualidade mais frequentes.

Quanto às correlações entre o nível de instrução e a posição/cargo que o entrevistado ocupa e o tempo que o pesquisado trabalha na área de logística, pode-se verificar que o valor absoluto do teste estatístico excede o valor crítico, concluindo-se, com 95\% e 99\%, que há correlação entre os dados. Nesse sentido, observa-se que, quanto maior o grau de instrução e a experiência na área, melhor é o cargo ocupado. Ao observar a correlação entre a variável tarifa de transporte cobrada e percentual de produto transportado por cabotagem, observa-se uma plena correlação, $\operatorname{com} \rho=0,96$, o que originou a hipótese H5: quanto menor a tarifa de transporte, maior o percentual de produto transportado por cabotagem.

Finalmente, verificou-se que existiam correlações muito fortes entre o tempo de trabalho na área de logística e o conhecimento de cada termo utilizado na cabotagem, com $\rho$ entre 0,95 e 0,97. Tal correlação se dá em virtude do maior contato do profissional com a atividade, e, consequentemente, sua familiaridade com os termos mais utilizados na área. Dessa forma, todas as correlações foram confirmadas como sendo "muito fortes", pois estavam dentro dos intervalos de $\rho$ assim designados.

\subsection{Diagnóstico do setor no Porto de Suape}

Conforme os dados analisados, a maior parte das empresas entrevistadas é considerada de grande porte e a modalidade mais utilizada é a "porta a porta". Segundo a pesquisa realizada, nessas empresas o uso do modal marítimo de carga conteinerizada é responsável por cerca de 5\% do total transportado, o que ratifica o enorme potencial de crescimento desse modal nas empresas em questão. Quanto aos fatores que aumentariam sua participação, destacou-se o menor custo total do frete, associado à maior confiabilidade nos prazos.

ldentificou-se ainda que em aproximadamente metade das organizações o transporte representa entre 10\% e 30\% nos custos dos produtos vendidos/ comprados e que a maior parte das empresas obtém redução acima de 10\% no frete ao utilizar a cabotagem ao invés do transporte rodoviário. Além disso, com base na análise inferencial, observou-se grande correlação entre o tamanho da empresa e o impacto financeiro nos seus custos de transporte.

Como observado na revisão da literatura e ratificado pela pesquisa, o transporte de cabotagem é mais barato que o rodoviário. Entretanto, o primeiro vem aumentando o valor do frete nos últimos três anos, devido ao fato de o preço ofertado pelos armadores ser construído a partir da pesquisa do frete utilizado pelo transporte rodoviário, seu principal concorrente.

Outro aspecto que pode ser inferido da percepção do cliente é que os armadores necessitam aperfeiçoar suas estruturas logísticas a partir de investimentos na renovação da frota, aquisição de centros de distribuição, aquisição de frota própria para transportes na modalidade "porta a porta", terceirização de operadores melhor qualificados, entre outros, o que agrega valor para o modal, mas, em contrapartida, aumenta os custos e, consequentemente, o valor dos fretes. Além disso, o aumento dos custos nos portos brasileiros e no bunker ocasiona a necessidade de repasse de gastos para o preço dos fretes.

Identificou-se ainda que a maioria dos profissionais que se encontra à frente da contratação do transporte possui nível superior ou especialização, além de experiência na área de logística superior a nove anos. Esse nível de qualificação e experiência profissional certamente contribui para um maior conhecimento das terminologias e modalidades empregadas na área, mesmo aquelas não encontradas na literatura, assim como melhores condições técnicas para a tomada de decisão quanto ao uso da cabotagem. Com relação aos termos menos conhecidos pelos entrevistados, que são o DMM, o FUE e o detation, levantou-se a hipótese de que o baixo conhecimento desses termos 
está atrelado ao maior uso da modalidade "porta a porta”, na qual toda a gestão do transporte é feita pelo armador. Essa correlação foi confirmada por meio dos testes estatísticos utilizados na análise inferencial dos dados.

Como mencionado anteriormente, a taxa de seguro para o transporte de cabotagem deve ser menor que para o rodoviário, já que ocorre menor exposição da carga à sinistralidade ao longo do percurso. Entretanto, a pesquisa mostra que poucas empresas usufruem do desconto no seguro ao utilizar a cabotagem, provavelmente devido ao desconhecimento dos contratantes acerca dos benefícios advindos do uso desse modal, pelo fato desses não comunicarem à seguradora o percentual de carga transportado por cabotagem, assim como a falta de uma base histórica de dados confiáveis sobre a efetiva redução de sinistros, que poderia ser utilizada como argumento para a negociação com as seguradoras.

Quanto às rotas de cabotagem existentes no porto, a mais utilizada tem como origem Pernambuco e, como destino, Amazonas. Essa possui o menor transit time da cabotagem com relação ao transporte rodoviário, pois enquanto o modal marítimo leva uma média de oito dias da origem ao destino, o rodoviário possui tempo de trânsito com média de 14 dias. Ademais, o preço do frete marítimo é inferior na referida rota. Em seguida, encontram-se as rotas qte têm como origem São Paulo e Santa Catarina e, como destino, Pernambuco, que possuem o custo do frete da cabotagem menor que o do transporte rodoviário.

Além dos percursos atuais, identificou-se que a rota com origem em Pernambuco e destino ao Pará, ainda inexistente, possui elevada demanda por parte dos entrevistados, pois esse trajeto possui carência de transporte, dificuldades de acesso logístico, além de elevado preço do frete rodoviário. Entretanto, a inclusão de uma nova rota de cabotagem requer demanda de carga para embarque e desembarque nos portos a serem introduzidos, de modo a garantir um melhor balanceamento de contêineres, o que garantiria fluxo de produtos na ida e na volta. A demanda por uma nova rota possibilita aos armadores um indicativo a ser analisado quanto à viabilidade comercial, operacional e estratégica.

Com relação aos serviços agregados ao transporte de cabotagem, as empresas valorizam o cumprimento do horário de coleta e entrega e a disponibilidade de contêineres e veículos, entre outros. Além disso, o menor custo do frete foi citado por várias empresas como fator determinante para o aumento da participação da cabotagem no transporte de cargas. Ademais, constatou-se que há um uso combinado dos armadores, ou seja, a empresa contratante utiliza vários armadores no transporte de suas cargas.
0 diagnóstico apresentado neste estudo permite às empresas transportadoras de cabotagem um melhor entendimento sobre a percepção dos clientes acerca do modal, assim como elementos que poderão ser úteis para as tomadas de decisão quanto aos serviços e aos fretes oferecidos no Porto de Suape. Por outro lado, oferece aos gestores e contratantes de frete um melhor conhecimento das terminologias empregadas na cabotagem e das modalidades utilizadas no mercado.

\section{Considerações finais}

0 principal objetivo deste trabalho foi realizar um diagnóstico sobre a percepção dos clientes do Porto de Suape sobre a cabotagem e, a partir daí, identificar os fatores de competitividade desse modal em relação ao transporte rodoviário, bem como os fatores que agregam valor no uso dos serviços oferecidos pelos armadores. Os resultados encontrados servem de base para as tomadas de decisão dos potenciais clientes do serviço e para os armadores de cabotagem em sua estratégia de mercado.

Como a área deste estudo ainda apresenta carência de conhecimento, realizou-se um estudo exploratório; as relações causais encontradas nesse tipo de estudo não são confirmatórias. Nesse sentido, com base nos resultados encontrados, cinco hipóteses de pesquisa a serem testadas em pesquisa confirmatória futura foram levantadas, uma vez que o objetivo do presente estudo foi gerar conhecimento inicial, ou seja, o diagnóstico em relação à cabotagem no Porto de Suape, sob a perspectiva dos clientes.

0 levantamento de dados foi realizado em empresas que utilizam o Porto de Suape, Pernambuco, seja no embarque ou desembarque de mercadorias, e que empregam o transporte de cargas em contêineres. A pesquisa obteve uma taxa de retorno de $67 \%$, o que equivale a 30 empresas. Essa taxa pode ser atribuída ao insistente contato com as empresas para que respondessem ao questionário, assim como à imediata substituição da empresa quando não se obtinha resposta. Em contrapartida, a maior dificuldade encontrada foi o tempo da coleta de dados, que se estendeu por 3 meses e 18 dias.

Após a coleta dos dados, foram realizados testes estatísticos em um conjunto de variáveis, com o auxílio das ferramentas do Minitab 16.0. Tal análise identificou correlações fortes ou muito fortes entre as variáveis observadas. Entretanto, como a amostra utilizada foi não probabilística, os resultados do estudo são apenas válidos para o universo amostral, o que é coerente para a pesquisa exploratória, mas é limitado no que diz respeito à generalização estatística dos resultados. 
Como visão geral da pesquisa, apontou-se que a cabotagem é um meio de transporte economicamente viável, com custos normalmente menores que os do transporte rodoviário. No porto em questão, a maior demanda do serviço ocorre para a modalidade "porta a porta" e a maior parte dos contratantes faz uso combinado de armadores. Constatou-se ainda que os clientes possuem um bom conhecimento sobre as terminologias utilizadas no setor.

Dentre os critérios de qualidade classificados como importantes para o uso da cabotagem, destacam-se o menor custo de frete, a pré-reserva do espaço e o envio de confirmação no mesmo dia. Com relação à escolha do armador, fatores como o menor preço no frete e a confiabilidade nos prazos são fundamentais. Ademais, a maioria dos clientes valoriza o cumprimento do horário de coleta e entrega, a disponibilidade de contêiner e a disponibilidade do veículo.

Como trabalhos futuros, pode-se desenvolver um estudo confirmatório nos demais portos brasileiros, utilizando-se amostras probabilísticas, no intuito de validar ou refutar as hipóteses levantadas nesta pesquisa, realizar pesquisas relativas ao impacto do transporte de cabotagem no custo dos produtos movimentados e desenvolver um estudo sobre o percentual de sinistros ocorridos no transporte de cabotagem realizado em comparação ao transporte rodoviário.

Nesse contexto, com base neste trabalho e nos estudos propostos, pode-se alcançar um panorama geral da cabotagem, o que possibilitará um incremento na logística de transporte brasileira, com ganhos financeiros efetivos para as empresas e para o país, a partir de uma matriz de transporte mais equilibrada.

\section{Referências}

Almeida, A. T. (2001). Multicriteria Decision Making on Maintenance: Spares and Contracts Planning. European Journal of Operational Research, 129(2), 235-241. http:// dx.doi.org/10.1016/S0377-2217(00)00220-4

Ballou, R. H. (2006). Gerenciamento da Cadeia de Suprimentos/ Logística Empresarial (5th ed.). Porto Alegre: Bookman.

Bandeira, R. A. M., Mello, L. C. B. B., \& Maçada, A. C. G. (2012). Elementos de flexibilidade em contratos de terceirização logística: o caso de uma empresa de telecomunicações. Produção, 22(2), 237-248. http://dx.doi.org/10.1590/ S0103-65132012005000017

Bowersox, D. J., Cooper, M. B., \& Closs, D. J. (2006). Gestão Logística de Cadeias de Suprimentos. Porto Alegre: Bookman.

Bozarth, C. C., \& Handfield, R. B. (2008). Introduction to Operations and Supply Chain Management (2nd ed.). New Jersey: Prentice Hall.

Brasil. (1993). Lei $\mathrm{n}^{\circ} 8.630$ de 25 de fevereiro de 1993. Dispõe sobre o regime jurídico da exploração dos portos organizados e das instalações portuárias e dá outras providências. Diário Oficial da República Federativa do Brasil, fev. Retrieved from http://www.planalto.gov.br/ ccivil_03/leis/18630.htm.

Brasil. (2004). Lei $n^{\circ}$ 10.893, de 13 de Julho de 2004 Dispõe sobre Adicional ao Frete para a novação da Marinha Mercante - AFRMM e o Fundo da Marinha Mercante - FMM, e dá outras providências. Diário Oficial da República Federativa do Brasil, jul.

Brasil. (2008). Portaria $n^{\circ}$ 72, de 18 de março de 2008. Aprova a norma complementar que estabelece critérios e disciplina procedimentos para a utilização do Sistema Eletrônico de Arrecadação do Adicional do Frete para a Renovação da Marinha Mercante e para o pagamento ou a solicitação e concessão de benefícios e incentivos relativos ao AFRMM. Diário Oficial da República Federativa do Brasil, mar.

Carvalho, R. 0. (2009). Logística integrada na prestação de serviço de cabotagem: de porto a porto a porta a porta (Dissertação de Mestrado). Santos: Universidade Católica de Santos.

Ching, H. Y. (2010). Gestão de Estoques na Cadeia de Logística Integrada - Supply Chain (4th ed.). São Paulo: Atlas.

Confederação Nacional dos Transportes - CNT. (2006). Pesquisa Aquaviária, Portos Marítimos: longo curso e cabotagem. Retrieved from www.cnt.org.br/informacoes/ pesquisa/aquaviaria/2006.

Council of Supply Chain Management Professionals. (2010) Supply Chain Management Terms and Glossary. 1llinois. Retrieved from http://cscmp.org.

Cruz, S. M. L. (2011). Diagnóstico em relação ao transporte de cabotagem no porto de Suape: uma pesquisa exploratória (Dissertação de mestrado). Universidade Federal de Pernambuco, Recife.

Fachinello, A. L., \& Nascimento, S. P. (2008). Cabotagem como alternativa para o transporte de carnes da região Sul para o Norte/Nordeste brasileiro: um estudo de caso. Revista de Economia e Sociologia Rural, 46(4). http:// dx.doi.org/10.1590/S0103-20032008000400003

Fadda, E. A. (2007). Considerações sobre o transporte marítimo de cabotagem no Brasil. In Congresso PanAmericano de Engenharia Naval, Transporte Marítimo e Engenharia Portuária, São Paulo.

Finney, D. J. (1980). Statistics for biologistis. London: Chapman and Hall. http://dx.doi.org/10.1007/978-94009-5855-5

Goularti Filho, A. (2010). A trajetória da Marinha Mercante Brasileira: administração, regime jurídico e planejamento. Pesquisa \& Debate, 21(2).

Guia Marítimo. (2011). Gargalos portuários prejudicam competitividade. Retrieved from http://www. guiamaritimo.com.br/nota.

Hair Junior, J. F., Babin, B., Money, A. H., \& Samouel, P. (2005). Fundamentos de métodos de pesquisa em administração. Porto Alegre: Bookman.

Instituto de Pesquisa Aplicada - IPEA. (2010). Eixo do desenvolvimento brasileiro. Portos brasileiros: diagnóstico, políticas e perspectivas. IPEA. Série n. 48.

Keedi, S. (2006). Transportes, unitização e seguros internacionais de carga: prática e exercícios (3. ed.). São Paulo: Aduaneiras. 
Logística Intermodal S/A. LOG-IN - (2010). Prospecto Definitivo de Oferta Pública de Ações.

Mendonça, P. C. C., \& Keedi, S. (1997). Transporte e Seguros no Comércio Exterior. São Paulo: Aduaneiras.

Moura, D. A., \& Botter, R. C. (2011). 0 transporte por cabotagem no Brasil - Potencialidade para a intermodalidade visando a melhoria do fluxo logístico. Produção Online, 11(2), 595-617.

Notteboom, T., \& Rodrigue, J. (2008). Containerisation, Box Logistics and Global Supply Chains: The Integration of Ports and Liner Shipping Networks. Maritime Economics \& Logistics, 10, 152-174. http://dx.doi.org/10.1057/ palgrave.mel.9100196

Oliveira, C. T. (2000). Modernização dos portos. São Paulo: Aduaneiras.

Portal Naval. (2010). Indústria naval: os próximos passos. Retrieved from http://www.portalnaval.com.br/.
Salido, M. A., Rodriguez-molins, M., \& Barber, F. (2012). A decision support system for managing combinatorial problems in container terminals. Knowledge-Based Systems, 29, 63-74. http://dx.doi.org/10.1016/j. knosys.2011.06.021

Souza, F. C., Souza, B. C., \& Silva, A. S. (2002). Elementos da pesquisa científica em medicina. Recife: Editora Universitária UFPE.

Triola, F. (2005). Introdução à estatística (9. ed.). Rio de Janeiro: LCT.

Tseng, Y., Yue, W. L., \& Taylor, M. A. P. (2005). The role of transportation in Logistics Chain. In Proceedings of the Eastern Asia Society for Transportation Studies, Bangkok.

Vergara, S. C. (2009). Projetos e relatórios de pesquisa em administração. São Paulo: Atlas.

Wanke, P. F., \& Affonso, C. R. (2011). Determinantes da eficiência da escala no setor brasileiro de operadores logísticos. Produção, 21(1), 53-63. http://dx.doi. org/10.1590/S0103-65132010005000045

\title{
Coastal shipping transport in Port of Suape - Pernambuco: an exploratory research
}

\begin{abstract}
The use of containers has a significant effect on the volume of products handled for import and export in Brazilian ports. Thus, materials handling via coastal shipping have been shown to be a viable alternative for transporting loads in the country. This study aimed to identify the factors of competitiveness of costal shipping companies located in port of Suape, Pernambuco. For this, we applied a questionnaire to collect data on corporate customers of the port, and carried out a statistical analysis to obtain a diagnosis on this modal. The results provide insight into customer opinion about coastal shipping lines and the aspects that bring differentiation in the core transport activity performed by the owner and most important to the customers. These results allow ship owners to reassess its strategy in the market and customers with a broad vision, which will assist in decision making in relation to transport strategy chose.
\end{abstract} Keywords

Supply Chain. Logistics. Transportation. 